TITLE:

\title{
Non-linear analyses of strain in flip chip packages improved by the measurement using the digital image correlation method
}

\section{$\operatorname{AUTHOR(S):~}$}

Ikeda, Toru; Kanno, Toshifumi; Shishido, Nobuyuki; Miyazaki, Noriyuki; Tanaka, Hiroyuki; Hatao, Takuya

\section{CITATION:}

Ikeda, Toru ... [et al]. Non-linear analyses of strain in flip chip packages improved by the measurement using the digital image correlation method. Microelectronics Reliability 2013, 53(1): 145-153

\section{ISSUE DATE:}

2013-01

URL:

http://hdl.handle.net/2433/169726

\section{RIGHT:}

C 2012 Elsevier Ltd.; この論文は出版社版でありません。引用の際には 出版社版をご確認ご利用ください。; This is not the published version. Please cite only the published version. 


\title{
Non-linear analyses of strain in flip chip packages improved by the measurement using the digital image correlation method
}

\author{
Toru Ikeda ${ }^{* a}$, Toshifumi Kanno ${ }^{* a}$, Nobuyuki Shishido ${ }^{* b}$, Noriyuki Miyazaki ${ }^{* a}$, Hiroyuki \\ Tanaka $^{* c}$, Takuya Hatao ${ }^{{ }^{*} \mathrm{c}}$ \\ ${ }^{* a}$ Kyoto University, Yoshida-Honmachi, Sakyo-ku, Kyoto, 606-8501, Japan. \\ ${ }^{*}$ Nagoya Institute of Technology, Gokiso-cho, Showa-ku, Nagoya, Aichi, 466-8555, Japan \\ ${ }^{{ }^{*} \mathrm{c} S u m i t o m o}$ Bakelite, Kiyohara Industrial Park, Utsunomiya, Tochigi, 321-3231, Japan.
}

\begin{abstract}
Numerical methods like the finite element (FE) method are often used to evaluate the reliability of electronic packages. However, the accuracy of non-linear numerical analyses should be confirmed by experimental measurements. In this study, we evaluated the strain distribution in flip chip (FC) packages with multi-layered printed circuit boards (PCBs) by combining the digital image correlation method (DICM) and the non-linear FE method, considering the viscoelasticity of resins and the elastoplasticity and creep of solder alloy. Four types of FC package consisting of two types of buildup (BU) resin and two types of underfill (UF) resin were evaluated. The distributions of strain on the cutting sections of FC packages were measured using the DICM with microphotographs obtained by a confocal laser scanning microscope (CLSM). The strain measurements showed that the UF resin with the low coefficient of thermal expansion (CTE) reduced thermal strain around a solder bump, and the $\mathrm{BU}$ resin with the low CTE reduced the strain concentration along the interface between a $\mathrm{Si}$ chip and a solder bump. We performed the non-linear FE analyses while taking into account the viscoelastic Poisson's ratio of the UF resin and the constant instantaneous Poisson's ratio. The result of the FE analyses with the constant instantaneous Poisson's ratio did not correspond with the strain measurements using the DICM. The normal strain in a solder bump was less than that obtained by the measurement, and the direction of a shear strain band in a solder bump was different from that measured using the DICM. On the other hand, the FE analyses considering the viscoelastic Poisson's ratio showed good agreement with the strain measurements using the DICM. The strain measurement using the DICM improved the accuracy of the non-linear FE analysis of micro electronic packages effectively.
\end{abstract}

\section{Introduction}


The demands for the miniaturization of electronic packages and the further development of their performance have driven the development of new micro electronic packaging techniques. One of the micro electronic packages is the flip chip (FC) package with a multi-layered printed circuit board (PCB). In the FC package, a silicon chip is directly attached to the PCB facedown to decrease the size of the package and increase the transmission speed. A multi-layered PCB is also effective to decrease the size of a package. The evaluation of the mechanical reliability of a FC package with multi-layered PCB is very important because of thermal stress caused by the mismatch of the coefficient of thermal expansion (CTE) between many components [1]-[3].

In the development of packaging technology, reliability evaluation has become increasingly important. Numerical methods like the finite element (FE) method are often used to evaluate the reliability of electronic packages, but the accuracy of numerical analysis is not always assured, because some of the materials in a package may have non-linear material properties such as the viscoelasticity of resin and the elastoplasticity and creep of solder alloy. It is therefore necessary that we confirm the accuracy of the numerical analyses by experimental measurements. Measuring the warpage of a package during thermal loading is important to confirm any numerical analyses of thermal deformation, but such measurement may not be sufficient to confirm the accuracy of a numerical analysis. Thus, the direct measurement of stress or strain fields in the microstructures of packages were performed using laser Raman spectroscopy [4] and laser interferometry techniques[5]-[7]. Kishi et al. [5] and Liu et al. [6] measured the displacement in BGA packages using the laser Moiré interferometry. Mikel et al. [7] measured the displacement in a flip chip package also using the laser Moiré interferometry. The digital image correlation method (DICM) [8]-[10] is also useful to measure the strain distributions. In particular, the DICM with microphotography can be efficiently applied to the measurement of strain fields in the microstructures of packages. In these studies, the authors measured displacement in electronic packages. However, they did not compare their measurement with the numerical analyses.

In this study, we examined the strain distribution in FC packages with multi-layered PCBs by combining the DICM and the non-linear FE method while considering the viscoelasticity, elastoplasticity and creep factors. We evaluated four FC packages consisting of two types of buildup (BU) resin and two types of underfill (UF) resin. By comparing the measurements and the FE analyses, we verified the accuracy of the FE analyses and investigated the effect of constitutive models of materials on the accuracy of the FE analyses.

Among the non-linear materials in the FC packages, the viscoelasticity of UF resin has a great influence on the reliability of solder joints [11]-[13]. The isotropic viscoelasticity of UF 
resin has been generally modeled by the relaxation modulus, neglecting the time-temperature dependence of Poisson's ratio. This might seriously affect the results of FE analyses because the volume change of UF resin may be underestimated.

In this study we examined the effects of two kinds of UF resin and two kinds of BU resin on the strain distribution in FC packages during thermal loading using the DICM with microphotographs obtained by a confocal laser scanning microscope (CLSM).We determined the viscoelastic properties of UF resins, which were time-temperature dependent on the relaxation moduli and Poisson's ratios, by stress relaxation tests, and we then performed FE analyses of FC packages while taking into account the time-temperature dependence of Poisson's ratios of UF resins. We also performed FE analyses with constant instantaneous Poisson's ratios of UF resins. Finally, we compared the strain distributions between the FE analyses and the measurements using the DICM. As part of the comparisons, we investigated the influence of the time-temperature dependence of Poisson's ratios on the strain distributions in FC packages. We discuss the improvement of the accuracy of the FE analysis of electronic packages using the strain measurement by the DICM.

\section{Measurement of strain distribution in FC package under thermal stress}

\subsection{Four types of FC package with multi-layered PCBs}

We made four types of FC package with multi-layered PCBs using two types of UF resin and two types of $\mathrm{BU}$ resin. A schematic of the cross-sectional structure of a FC package is shown in Fig. 1. The CTEs and Young's moduli of these materials are shown in Fig. 2. The combinations of UF resins and BU resins in FC packages are shown in Table 1. The CTEs and Young's moduli were obtained using a TMA (thermo-mechanical analyzer) and a DMA (dynamic mechanical analyzer), respectively. Solder bumps in FC packages are made of Sn-3.0Ag-0.5Cu.

Thermal cycle tests for the four types of FC packages were carried out as shown in Fig. 3. The results show the disconnection rates of respective FC packages after 1000 thermal cycles. The failure rates of the Nos. 2 and 4 packages with UF-2 resin, which has lower CTE and higher glass transition temperature (Tg), were zero. In the comparison between No. 1 and No. 3 packages with higher CTE of UF resins, the failure rate of package No. 3 with BU-2 resin was less than that of package No. 1 with BU-1 resin. According to the results, FC packages with the lower CTE and higher Tg UF and BU resins had higher reliability than those with the higher 
CTE and lower Tg UF and BU resins. In particular, the material properties of UF resins had great influence on the reliability of FC packages.

\subsection{Preparation for strain measurement}

We cut out a part of each FC package, as shown in Fig. 4, and polished the cross-sections of the specimen. We took digital images using a CLSM (OLYMPUS LEXT OLS3000) to measure the strain distributions on the cross-sections of the specimens by the DICM [10]. The specimens were subjected to thermal loading in a heat chamber, as shown in Fig. 5. The surfaces of the cross-sections were painted with ink spray to draw random patterns for the DICM, as shown in Fig. 6. The temperature in the heat chamber was changed from $25^{\circ} \mathrm{C}$ to $125^{\circ} \mathrm{C}$, as shown in Fig. 7. The strain distributions were measured at every $25^{\circ} \mathrm{C}$ of temperature change, and we obtained the total strain distributions caused by heating from $25^{\circ} \mathrm{C}$ to $125^{\circ} \mathrm{C}$.

\subsection{Results of strain measurement}

Fig. 8 shows the shear $\left(\varepsilon_{x y}\right)$ and normal $\left(\varepsilon_{y}\right)$ strain distributions around the solder bumps beside the edges of Si chips by the DICM. Strain in and around solder bumps on the No. 3 and No. 4 specimens with UF-2 was lower than that on the No. 1 and No. 2 specimens. The strain along the interface between a solder bump and a Si chip on the No. 3 specimen is slightly lower than that on the No. 1 specimen, but the difference was not significant. These measured strain distributions obtained using the DICM can explain the result of the thermal cycle test presented in Fig. 3 qualitatively.

\section{Measurement of the viscoelasticity of UF resins}

\subsection{Linear isotropic viscoelastic theory}

According to the linear viscoelastic theory [14-17], the stress and strain relationship at time $t$ is described by the following integral expression:

$$
\sigma_{y}(t)=\int_{-\infty}^{t} E(t-\tau) \frac{d \varepsilon_{y}(\tau)}{d \tau} d \tau
$$

where $\sigma_{y}, E, \varepsilon_{y}$ and $t$ are the stress, relaxation modulus, strain and time, respectively. If the constant strain $\varepsilon_{y 0}$ is assumed to be suddenly applied at time $t=0$ in the stress relaxation test, the expression (1) can be written as 


$$
\sigma_{y}(t)=E(t) \cdot \varepsilon_{y 0}
$$

For the volumetric change of the viscoelasticity under uniaxial tensile loading, the relationship between tensile axial strain $\left(\varepsilon_{y}\right)$ and lateral direction strain $\left(\varepsilon_{x}\right)$ is given by the following equation [15]:

$$
-\varepsilon_{x}(t)=\int_{-\infty}^{t} v(t-\tau) \frac{d \varepsilon_{y}(\tau)}{d \tau} d \tau
$$

where $v$ is Poisson's ratio. If the constant strain $\varepsilon_{y 0}$ is assumed to be applied in the stress relaxation test, the expression (3) can also be written as

$$
\varepsilon_{x}(t)=-v(t) \cdot \varepsilon_{y 0}
$$

In the case of isotropic material, two dependent parameters such as $E$ and $v$ can be obtained by the stress relaxation test.

\subsection{Preparation for the stress relaxation test (SRT)}

We performed the stress relaxation test (SRT) with the DICM and measured the variation of stress, axial strain and lateral strain. The experimental system is shown in Fig. 9. During the test, the digital images of the surface on rectangular specimens of UF resins were taken by a complementary metal-oxide semiconductor (CMOS) camera with a microscope lens. The size of a specimen was about $45 \times 10 \times 1 \mathrm{~mm}$, and the surfaces were painted by ink spray to draw random patterns.

The displacement of a specimen was increased to the prescribed initial tensile strain within about one second. The initial tensile strains of UF-1 and UF-2 were $0.45 \%$ and $0.35 \%$, respectively, at room temperature, and these strains were lower than the respective yield strains. To prevent vibration noise just after applying the load, we initiated the capture of surface photographs 10 seconds after the initial loading and finished at 1000 seconds. These measurements were implemented at various temperatures. The strain of a UF-1 resin specimen was measured every $10^{\circ} \mathrm{C}$ twice started from $5^{\circ} \mathrm{C}$ and $10^{\circ} \mathrm{C}$, because it was difficult to measure every $5^{\circ} \mathrm{C}$ due to the rapid relaxation. Eventually, the strain of UF-1 resin specimens was obtained every $5^{\circ} \mathrm{C}$ up to $77.2^{\circ} \mathrm{C}$. On the other hand, the strain of a UF-2 resin specimen was measured every $10^{\circ} \mathrm{C}$ up to $101.0^{\circ} \mathrm{C}$ by just one measurement because of the slow relaxation. At each temperature, the temperature was stabilized for more than 30 minutes before loading.

\subsection{Results of the stress relaxation test}

Fig. 10 shows the distributions of displacement on the surface of the specimen of UF-1 
resin measured by the DICM at $31.7{ }^{\circ} \mathrm{C}$. The strain in the regions surrounded by broken lines was averaged. The variations of tensile axial strain $\left(\varepsilon_{y}\right)$ and lateral strain $\left(\varepsilon_{x}\right)$ with the relaxation time are shown in Fig. 11. Relaxation moduli of UF resins were calculated from the mean strain and the mean stress of specimens using Eq. (2) for respective temperatures to reduce the influence of the scattered strain measurements. The variations of relaxation moduli at respective temperatures with the relaxation time are shown in Fig. 12. The results show smooth curves of relaxation moduli of UF-1 and UF-2 at respective temperatures. On the other hand, Poisson's ratios were calculated by domain-averaged axial and lateral strains using Eq. (4). The relaxation moduli, as shown in Fig. 12, are used to build the relaxation master curves under the assumption of time-temperature superposition theory, which is based on the thermorheological simplicity of UF resins. Obtained relaxation master curves are shown in Fig. 13. Here, the reference temperatures $\left(T_{0}\right)$ in UF-1 and UF-2 resins were $57.2{ }^{\circ} \mathrm{C}$ and $71.5{ }^{\circ} \mathrm{C}$, respectively. The shift factors were well approximated by the Arrhenius equations as follows:

$$
\begin{gathered}
\log \mathrm{a}_{T}=\beta \frac{\Delta H}{\mathrm{R}}\left(\frac{1}{T}-\frac{1}{T_{0}}\right) \\
\mathrm{UF}-1: \beta \frac{\Delta H}{\mathrm{R}}=\left\{\begin{array}{c}
26589 \\
14805
\end{array}, \mathrm{UF}-2: \beta \frac{\Delta H}{\mathrm{R}}=\left\{\begin{array}{ll}
20396 & T \geq T_{0} \\
14203 & T<T_{0}
\end{array} \quad[\mathrm{~K}]\right.\right.
\end{gathered}
$$

where $\mathrm{a}_{T}, \Delta H, \mathrm{R}$ and $T$ are the shift factor, activation energy, gas constant and absolute temperature, respectively, and $\beta$ is a constant value $(\beta=1 / 2.303)$. The master curves of Poisson's ratios were also made, as shown in Fig. 14. The same shift factors with the relaxation moduli were assumed for respective Poisson's ratios, because the data of Poisson's ratios were too scattered to obtain the shift factors from them. The master curves of relaxation moduli and Poisson's ratios were fitted by the Prony series as follows:

$$
\begin{aligned}
& E(t)=E_{\infty}+\sum_{k=1}^{n} E_{k} \exp \left(-t / \tau_{k}\right) \\
& v(t)=v_{\infty}+\sum_{k=1}^{n} v_{k} \exp \left(-t / \tau_{k}\right),
\end{aligned}
$$

where $E_{k}$ and $v_{k}$ are participation factors and $\tau_{k}$ is the relaxation time. The participation factors and the relaxation times principally can be fitted by the Prony series. We selected the relaxation times to cover all data points and decided the participation factors using the least squares approximation method. The master curves must be monotonically decreasing for relaxation moduli and monotonically increasing for Poisson's ratios, so all participation factors of relaxation moduli and Poisson's ratios should be negative and positive, respectively. We 
removed the terms of the Prony series that had irregular signs and used the least squares approximation method to determine the remaining participation factors again. This procedure was repeated until all the participation factors of relaxation moduli and Poisson's ratios became positive and negative values, respectively. The fitting curves of relaxation moduli and Poisson's ratios by the Prony series are demonstrated in Figs. 13 and 14, respectively.

\section{The FE analyses of FC packages}

\subsection{Implementation of the viscoelastic model in the FE method}

For analyses of the stress and strain fields in FC packages, a commercial FE package, MSC. Marc $^{\text {TM }}$, was used. It can analyze the viscoelastic problem to satisfy the thermorheologically simple behavior. This analysis requires the Prony series of the master curves of relaxation shear modulus $G(t)$ and relaxation bulk modulus $K(t)$ and the shift factor [18]. The shear and bulk moduli, $G(t)$ and $K(t)$, are related to the measured relaxation modulus $E(t)$ and Poisson's ratio $v(t)$ on the basis of the correspondence principle following Laplace transform relations [15]:

$$
\begin{gathered}
\bar{E}(s)=2 \bar{G}(s)[1+s \bar{v}(s)] \\
\bar{E}(s)=3 \bar{K}(s)[1-2 s \bar{v}(s)],
\end{gathered}
$$

where $s$ is the Laplace operator, and $\bar{E}(s), \bar{G}(s)$ and $\bar{K}(s)$, are Young's modulus and the shear and bulk moduli in the Laplace space, respectively. The inverse Laplace transforms of these equations are given by the convolution integral formulations as follows:

$$
\begin{aligned}
& E(t)=2 G(t)+2 \int_{0}^{t} G(t-\tau) \frac{d v(\tau)}{d \tau} d \tau \\
& E(t)=3 K(t)-6 \int_{0}^{t} K(t-\tau) \frac{d v(\tau)}{d \tau} d \tau
\end{aligned}
$$

These integral formulations must be solved using the discrete approximation. The first-order accurate discretizations are described as follows [16]:

$$
\begin{gathered}
G_{n}=\frac{E_{n}-G_{g}\left[v_{n}-v_{n, 1}\right]-\sum_{i=1}^{n-1} G_{i}\left[v_{n, i-1}-v_{n, i+1}\right]}{2+v_{g}+v_{n, n-1}} \\
K_{n}=\frac{\frac{1}{3} E_{n}+K_{g}\left[v_{n}-v_{n, 1}\right]+\sum_{i=1}^{n-1} K_{i}\left[v_{n, i-1}-v_{n, i+1}\right]}{1-v_{g}-v_{n, n-1}}
\end{gathered}
$$


Here, $f_{g}=f($ glassystate $), f_{n}=f\left(t_{n}\right), f_{n, i}=f\left(t_{n}-t_{i}\right)$. The relaxation shear and bulk moduli can be numerically obtained using the Prony series of the measured relaxation Young's moduli and Poisson's ratios. The numerically obtained shear and bulk moduli were also fitted by the Prony series for the input data for Marc ${ }^{\mathrm{TM}}$. These fitting curves by the Prony series are shown in Fig. 15. The coefficients of the Prony series for $E(t), G(t), K(t)$ and $v(t)$ are shown in Table 2.

In this study, to examine the effect of the time-temperature dependence of Poisson's ratio on the accuracy of the FE analyses, we calculated another relaxation bulk modulus, $K\left(t, v_{0}\right)$, without considering the viscoelastic behavior of Poisson's ratio, using the following equation:

$$
K\left(t, v_{0}\right)=\frac{2\left(1+v_{0}\right)}{3\left(1-2 v_{0}\right)} G(t),
$$

where $v_{0}$ is the constant instantaneous Poisson's ratio (UF-1 $: 0.3795$, UF-2 $: 0.2414$ ). The effect of Poisson's ratio on the shear modulus was not investigated, because the effect was much less than that for the bulk modulus, and the relaxation shear modulus can be easily obtained by the relaxation shear test and the dynamic mechanical analysis (DMA). The comparison of relaxation bulk modulus between $K(t)$ and $K\left(t, v_{0}\right)$ is shown in Fig. 16. As shown in the figure, the bulk modulus considering the effect of Poisson's ratio, $K(t)$, is much larger than that with the constant instantaneous Poisson's ratio, $K\left(t, v_{0}\right)$, and the difference between $K(t)$ and $K\left(t, v_{0}\right)$ is significant when the Poisson's ratio is closer to 0.5 at longer time and higher temperature.

\subsection{FE model of FC packages}

The FE analyses were carried out using MSC. Marc ${ }^{\mathrm{TM}}$. A symmetrical quarter of each specimen of the FC package was modeled by a three-dimensional FE model, as shown in Fig. 17. The FE model consists of a global and a local model. The local model includes a detailed structure of solder joints around a chip edge. This model contacts the global model so that the displacements on the surfaces of two models correspond each to other along the interface between them using "the glue contact option" of Marc ${ }^{\mathrm{TM}}$. In the whole model, the volume ratios of solder and copper correspond with those of the actual test specimen. The 3D FE element type used for the analyses was the linear hexagonal solid element.

\subsection{Material properties}

The elastoplastic and creep behaviors of the lead-free solder alloy were considered. The creep behavior of the solder alloy was assumed to be expressed by Norton's law, as follows [19]: 


$$
\begin{aligned}
& \dot{\varepsilon}_{c}=\exp (0.1595 T-50.841) \cdot \sigma^{n(T)}, \\
& n(T)=-0.0321 T+11.889,
\end{aligned}
$$

where $\dot{\varepsilon}_{c}$ is the creep strain rate. Table 3 shows the relationship between yield stress and plastic strain for the solder alloy. The measured viscoelastic behavior of UF resins was considered. BU resins were assumed to be isotropic linear elastic material with Poisson's ratio, $v=0.3$, because of the higher Tg. The Young's moduli and CTEs of BU and UF resins measured by the DMA and the TMA are shown in Fig. 2. We assumed the components of FC packages, except the UF resins and solder alloy, to be isotropic linear elastic materials, whose material properties are shown in Table 4.

\subsection{Thermal conditions in FE analyses}

In the FE analyses, the initial temperature in each FC package was set so that the warpage at room temperature $\left(25^{\circ} \mathrm{C}\right)$ in the $\mathrm{FE}$ analyses corresponded to the experimental measurements. Determined initial temperatures are shown in Table 5. In the table, the 'model GK' shows the viscoelastic model with $G(\mathrm{t})$ and $K(t)$ obtained by Eqs. (12) and (13), which consider the time-temperature dependence of Poisson's ratio of UF resin. The 'model G' shows the model with $G(\mathrm{t})$ obtained by Eq. (12), and $K\left(t, v_{0}\right)$ obtained by (14) which is calculated by the constant instantaneous Poisson's ratio. Each specimen of the FC package was cooled to $25^{\circ} \mathrm{C}$ from each stress free temperature at a rate of $0.5^{\circ} \mathrm{C} / \mathrm{min}$ and kept at $25^{\circ} \mathrm{C}$ for $10 \mathrm{~min}$ at the top of the $\mathrm{FE}$ analysis. Then, it was heated to $125^{\circ} \mathrm{C}$ so it would have the same temperature history as the corresponding strain measurement. The temperatures in the FC packages were assumed to be homogeneous because of the small size of the specimens.

\section{Evaluation of the FE analyses using the measurements by the DICM}

\subsection{Comparison among four types of FC package}

Figs. 18 and 19 showed the shear $\left(\varepsilon_{x y}\right)$ and normal $\left(\varepsilon_{y}\right)$ strain distributions around the solder bumps beside the edges of Si chips, which were calculated by the FE analyses using the model GK and the model G, respectively. In the results of both models, the packages of No. 2 and No. 4 with UF-2 showed lower strain in the solder bumps than did the packages of No. 1 and No. 3, and relatively agreed with the measurements by the DICM. However, the packages of No. 3 and No. 4 with BU-2 showed almost the same strain distribution as those of the packages of No. 1 and No. 2 with BU-1, respectively. One of the reasons for this small difference might be that the 
difference in material properties of BU resins in Fig. 2 applied to FE analyses was too small to affect the strain distribution. The material properties of BU resins in Fig. 2 were measured after a long curing time, and they might be different from those in the actual FC packages.

\subsection{Comparison between the viscoelastic models of UF resins}

We considered the influence of the time-temperature dependence of Poisson's ratios of UF resins on the strain distribution. The distributions of shear strain in the solder bumps for No. 1 and No. 3 with UF-1 shown in Fig. 18 (model GK) were concentrated from the upper left corner to the lower right corner. The directions of the shear strain bands correspond with those measured by the DICM, as shown in Fig. 8 (a). However, in the cases of No. 1 and No. 3 in Fig. 19 (model G), the directions of the shear strain bands were different from the measurements. On the other hand, the shear strain bands of No. 2 and No. 4 with UF-2 obtained by both models (GK and $\mathrm{G}$ ) are not much different from each other, and they show relatively good agreement with the measurements by the DICM regarding the magnitude of shear strain. The tensile strain, $\varepsilon_{y}$, in the solder bumps obtained by the model GK is larger than that obtained by the model G. This tendency is significant in the packages of No. 1 and No. 3 with UF-1. As shown in Fig. 16, the bulk moduli considering the viscoelastic Poisson's ratios, $K(t)$, is bigger than those assuming the constant Poisson's ratios, $K\left(t, v_{0}\right)$, at longer relaxation time, and it is more significant for UF-1 resin than UF-2 resin. This increase of the bulk modulus causes the bigger thermal volume expansion of UF resins in the model GK than that in model G, and the solder bumps were stretched between a Si chip and a PCB by the bigger thermal expansion of UF resin. The increased tensile strain obtained by the model GK corresponded well with that measured by the DICM.

\subsection{Change of the directions of shear strain bands in the solder bumps}

To clarify the reason for the change of the directions of shear strain bands in the solder bumps according to the viscoelastic model of UF resins, G and GK, we performed the following analyses for a single solder bump model, as shown in Fig. 20. We calculated the distributions of shear strain in a solder bump under a uniform shear strain with three different types of vertical load: (i) simple shear with no vertical load, (ii) shear stress with tensile vertical load, (iii) shear stress with compressive vertical load. Uniform shear strain was applied as the constant relative displacement of $2 \mu \mathrm{m}$ along the $x$-axis between a Si chip and a copper board, and vertical tensile and compressive loads of $2 \mathrm{MPa}$ were applied on the bottom surface of a copper board. 
Fig. 21 shows the distributions of shear stress in a solder bump under the combination of shear stress and three types of vertical load. The distribution under simple shear was similar to the measurement by the DICM for the packages of No. 2 and No. 4 with UF-2 resin. The distribution under the combination of shear stress and tensile vertical load was similar to the DICM measurement and the FE analyses with model GK for the packages of No. 1 and No. 3 with UF-1 resin. The distribution under the combination of shear stress and compressive vertical load was similar to the FE analyses with model G for the packages of No. 1 and No. 3 with UF-1.

According to these results, we found that the vertical stress in a solder bump moved the concentrated region of shear strain in the bump. As mentioned previously, the vertical load in a solder bump was greatly influenced by the value of Poisson's ratio. It is very important to consider the viscoelastic behavior of Poisson's ratio of UF resin whose volume is constrained by surrounding components. The measurement of the distribution of strain using the DICM and a microscope can improve the accuracy of the nonlinear numerical analysis of an electronic package effectively.

\section{Conclusions}

We evaluated the strain distributions around the solder bumps beside the edges of Si chips in four types of FC package with multi-layered PCBs using the DICM and FE analysis while considering the viscoelasticity of UF resin and the elastoplasticity and creep of solder alloy. According to the strain measurements using the DICM, UF resin with lower CTE and higher Tg reduced the thermal strain in solder bumps, and BU resin with lower CTE and higher Tg reduced the strain concentration along the interface between a Si chip and a solder bump.

We performed a stress relaxation test to obtain the viscoelastic properties of UF resin and found that the relaxation bulk modulus taking the time-temperature dependence of Poisson's ratio into account was much larger than that with the constant instantaneous value, especially for the UF-1 resin. We performed FE analyses of FC packages while taking into account the time-temperature dependence of Poisson's ratio of UF resin (model GK), and with the constant instantaneous value (model $G$ ). In the results of the FE analyses with the model $G$, the directions of shear strain bands in solder bumps were different from those measured using the DICM. The normal strain in solder bumps calculated by the FE analyses with the model G was less than that obtained by the measurement. However, the FE analyses with model GK showed 
good agreement with the strain measurements by the DICM.

To clarify the reason for the change in direction of a shear strain band in a solder bump, we calculated the distributions of shear strain in a solder bump under a uniform shear strain with three types of vertical loads. We found that the vertical stress in a solder bump changed the direction of a shear strain band in the bump.

The viscoelastic behavior of Poisson's ratio of UF resin, whose volume is constrained by surrounding components, must be considered to calculate the distribution of stress and strain around a solder bump in UF resin. The strain measurement using the DICM improved the accuracy of the non-linear FE analyses of micro electronic packages effectively.

\section{References}

[1] Reichl H, Schubert A and Topper M, Reliability of flip chip and chip size packages, Microelectronics Reliability, vol. 40, pp. 1243-1254, 2000.

[2] Kim DG, Kim JW and Jung SB, Evaluation of solder joint reliability in flip chip package under thermal shock test, Thin Solid Films, vol. 504, pp. 426-430, 2006.

[3] Pang JHL, Chong DYR and Low TH, Thermal cycling analysis of flip chip solder joint reliability, IEEE Transaction on Components and Packaging Technologies, vol. 24, pp. 705-712, 2001.

[4] Wolf ID, Jian C and van Spengen WM, The investigation of microsystems using Raman spectroscopy, Optics and Lasers in Engineering, vol. 36, pp. 213-223, 2001.

[5] Kishi T, Miki K and Koibuchi K, Mechanical behavior measurement of electronic devices by Moiré interferometry under thermal cycle test, Trans. JSME Series A, vol. 45, no. 2, pp. 232-239.

[6] Liu H, Basaran C, Catwright AN and Casey W, Application of Moiré Interferometry to determine strain fields and debonding of solder joints in BGA packages, IEEE Transactions on components and packaging technologies, vol. 27, no. 1, pp. 217-223, 2004.

[7] Miller MR, Mohammed I and Ho PS, Quantitative strain analysis of flip-chip electronic packages using phase-shifting moiré interferometry, Optics and Lasers in Engineering, vol. 36, pp.127-139, 2001.

[8] Bruck HA, McNeill SR, Sutton MA and Peters WH III, Digital image correlation using Newton-Raphson method of partial differential correction, Experimental Mechanics, vol. 38, pp. 86-92, 1998.

[9] Park S, Dhakal R, Lehman L and Cotts EJ, Grain deformation and strain in board level 
$\mathrm{SnAgCu}$ solder interconnects under deep thermal cycling, IEEE Transaction on Components and Packaging Technologies, vol. 30, 2007, pp. 178-185.

[10] Shishido N, Ikeda T and Miyazaki N, Strain measurement in a microstructure using digital image correlation for a laser-scanning microscopic image, Computer Modeling in Engineering \& Science, vol. 35, pp. 1-19, 2008.

[11] Sham ML, Kim JK and Park JH, Numerical analysis of plastic encapsulated electronic package reliability: Viscoelastic properties of underfill resin, Computational Materials Science, vol. 40, pp. 81-89, 2007.

[12] Tsai MY, Lin YC, Huang CY and Wu JD, Thermal deformations and stresses of flip-chip BGA packages with low- and high-Tg underfills, IEEE Transactions on Electronics Packaging Manufacturing, vol. 28, pp. 328-337, 2005.

[13] Wang TH, Lai YS and Wu JD, Effect of underfill thermomechanical properties on thermal cycling fatigue reliability of flip-chip ball grid array, Journal of Electronic Packaging, vol. 126, pp.560-564, 2004.

[14] O'Brien DJ, Sottos NR and White SR, Cure-dependent viscoelastic Poisson's ratio of epoxy, Experimental Mechanics, vol. 47, pp. 237-249, 2007.

[15] Tschoegl NW, Knauss WG and Emri I, Poisson's ratio in linear viscoelasticity - a critical review, Mechanics of Time-Dependent Materials, vol. 6, pp. 3-51, 2002.

[16] Ernst LJ, Zhang GQ, Jansen KMB and Bressers HJL, Time- and temperature- dependent thermo-mechanical modeling of a packaging molding compound and its effect on packaging process stresses, Journal of Electronic Packaging, vol. 125, pp. 539-548, 2003.

[17] Theocaris PS and Hadjijoseph C, Transient lateral contraction ratio of polymers in creep and relaxation, Kolloid-Zeitschrift und Zeitschrift für polymere, vol. 2, pp. 133-139, 1964.

[18] Marc2007r1 Volume A: Theory and User Information, MSC. Software, 2007.

[19] Qiang Y, Shibutani T and Kobayashi Y, RC227 Research reports, Japan Society of Mechanical Engineers, pp. 65-124, 2008, in Japanese. 
Table 1 Combination of BU and UF resins in FC packages.

\begin{tabular}{|c|c|c|c|c|}
\hline & No.1 & No.2 & No.3 & No.4 \\
\hline Buildup & BU-1 & BU-1 & BU-2 & BU-2 \\
\hline Underfill & UF-1 & UF-2 & UF-1 & UF-2 \\
\hline
\end{tabular}

Table 2 Coefficients of Prony series for both UF resins.

a) UF-1 resin

\begin{tabular}{ccccc}
\hline$\tau_{k}[\mathrm{Sec}]$. & $E_{k}[\mathrm{MPa}]$ & $v_{k}[-]$ & $G_{k}[\mathrm{MPa}]$ & $K_{k}[\mathrm{MPa}]$ \\
\hline $10^{-3}$ & 473.94 & 0 & 171.65 & 372.22 \\
$10^{-2}$ & 220.09 & -0.0047 & 89.76 & 0 \\
$10^{-1}$ & 496.65 & 0 & 178.13 & 811.50 \\
$10^{+0}$ & 572.69 & 0 & 210.85 & 0 \\
$10^{+1}$ & 1054.82 & -0.0324 & 425.97 & 0 \\
$10^{+2}$ & 1276.71 & -0.0154 & 463.80 & 0 \\
$10^{+3}$ & 1810.82 & -0.0197 & 645.05 & 1943.80 \\
$10^{+4}$ & 1306.54 & -0.0284 & 450.52 & 511.26 \\
$10^{+5}$ & 527.83 & -0.0067 & 175.91 & 3390.58 \\
$10^{+6}$ & 143.54 & -0.0090 & 48.96 & 373.52 \\
$10^{+7}$ & 36.21 & 0 & 10.97 & 1264.91 \\
$10^{+8}$ & 15.76 & 0 & 4.97 & 754.80 \\
$10^{+9}$ & 2.38 & 0 & 1.80 & 194.42 \\
$\infty$ & 30.0 & 0.4958 & 10.03 & 1187.65 \\
\hline
\end{tabular}

b) UF-2 resin

\begin{tabular}{ccccc}
\hline$\tau_{k}[\mathrm{Sec}]$. & $E_{k}[\mathrm{MPa}]$ & $v_{k}[-]$ & $G_{k}[\mathrm{MPa}]$ & $K_{k}[\mathrm{MPa}]$ \\
\hline $10^{-4}$ & 610.69 & 0 & 246.77 & 393.26 \\
$10^{-3}$ & 540.52 & -0.0121 & 249.94 & 87.55 \\
$10^{-2}$ & 797.28 & -0.0121 & 344.87 & 305.08 \\
$10^{-1}$ & 877.55 & -0.0121 & 371.12 & 333.47 \\
$10^{+0}$ & 1059.30 & -0.0152 & 438.37 & 610.22 \\
$10^{+1}$ & 1070.35 & -0.0281 & 457.18 & 115.52 \\
$10^{+2}$ & 1228.11 & -0.0648 & 509.45 & 0 \\
$10^{+3}$ & 1204.80 & 0 & 426.16 & 1410.72 \\
$10^{+4}$ & 829.95 & -0.0185 & 307.40 & 1069.19 \\
$10^{+5}$ & 448.10 & -0.0322 & 158.68 & 485.78 \\
$10^{+6}$ & 160.61 & 0 & 55.31 & 548.38 \\
$10^{+7}$ & 55.91 & 0 & 19.56 & 117.76 \\
$10^{+8}$ & 21.17 & 0 & 7.34 & 62.81 \\
$\infty$ & 100.0 & 0.4365 & 34.81 & 262.47 \\
\hline
\end{tabular}

Table 3 Relationship between yield stress and plastic strain of $\mathrm{SnAgCu}$ solder alloy.

\begin{tabular}{|c|c|c|c|c|c|c|c|}
\hline Temperature $\left[{ }^{\circ} \mathrm{C}\right]$ & -40 & -25 & $\mathbf{0}$ & 20 & 25 & 40 & $\mathbf{5 0}$ \\
\hline Plastic strain & \multicolumn{7}{|c|}{ Yield stress [MPa] } \\
\hline $\mathbf{0}$ & 29 & 27.5 & 25 & 23 & 22.5 & 21 & 19.9 \\
\hline 0.004 & 36.7 & 34.8 & 31.6 & 29 & 28.4 & 26.5 & 25.2 \\
\hline 0.021 & 48.4 & 45.9 & 41.7 & 38.3 & 37.5 & 35 & 33.3 \\
\hline Temperature $\left[{ }^{\circ} \mathrm{C}\right]$ & 60 & 75 & 80 & 85 & 100 & 120 & 125 \\
\hline Plastic strain & \multicolumn{7}{|c|}{ Yield stress [MPa] } \\
\hline $\mathbf{0}$ & 18.9 & 17.4 & 17 & 16.5 & 15.2 & 13.4 & 12.9 \\
\hline 0.004 & 23.9 & 22 & 21.5 & 20.9 & 19.2 & 16.9 & 16.4 \\
\hline 0.021 & 31.6 & 29.1 & 28.3 & 27.6 & 25.3 & 22.4 & 21.6 \\
\hline
\end{tabular}


Table 4 Material properties of components in FC packages.

\begin{tabular}{|c|c|c|c|c|}
\hline You & '’s modulus[GPa] & CTE[ppm/K] & Poisson's ratio & $\mathrm{Tg}\left[{ }^{\circ} \mathrm{C}\right]$ \\
\hline Silicon & 131 & 3 & 0.28 & - \\
\hline Copper & 65 & 17 & 0.343 & - \\
\hline Solder resist & $2.6 / 0.067$ & $55 / 140$ & 0.31 & 107 \\
\hline Polyimide & 2.9 & 50 & 0.3 & - \\
\hline Substrate core & $10.6 / 4.8$ & $14 / 25$ & 0.2 & 170 \\
\hline Solder bump & 40 & 23 & 0.3 & \\
\hline
\end{tabular}

Table 5 Stress free temperatures for the respective FE analyses.

\begin{tabular}{|l|c|c|c|c|}
\hline$\left[{ }^{\circ} \mathrm{C}\right]$ & No. 1 & No. 2 & No. 3 & No. 4 \\
\hline Model GK & 195 & 187 & 189 & 171 \\
\hline Model G & 184 & 183 & 178 & 168 \\
\hline
\end{tabular}




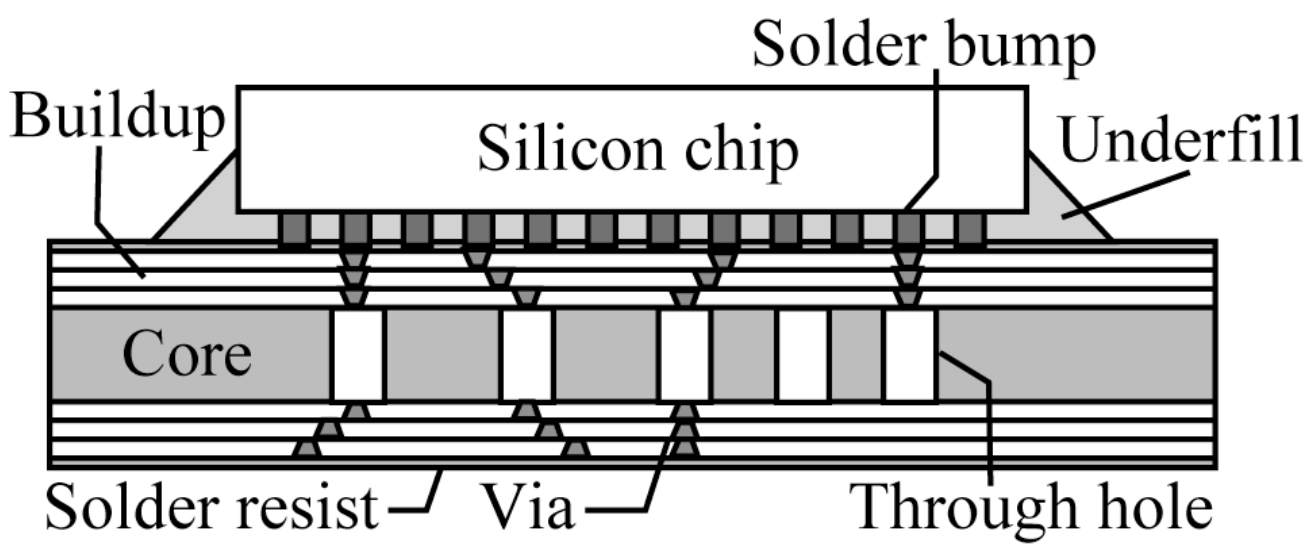

Fig. 1 Schematic of cross sectional structure of a FC packages.
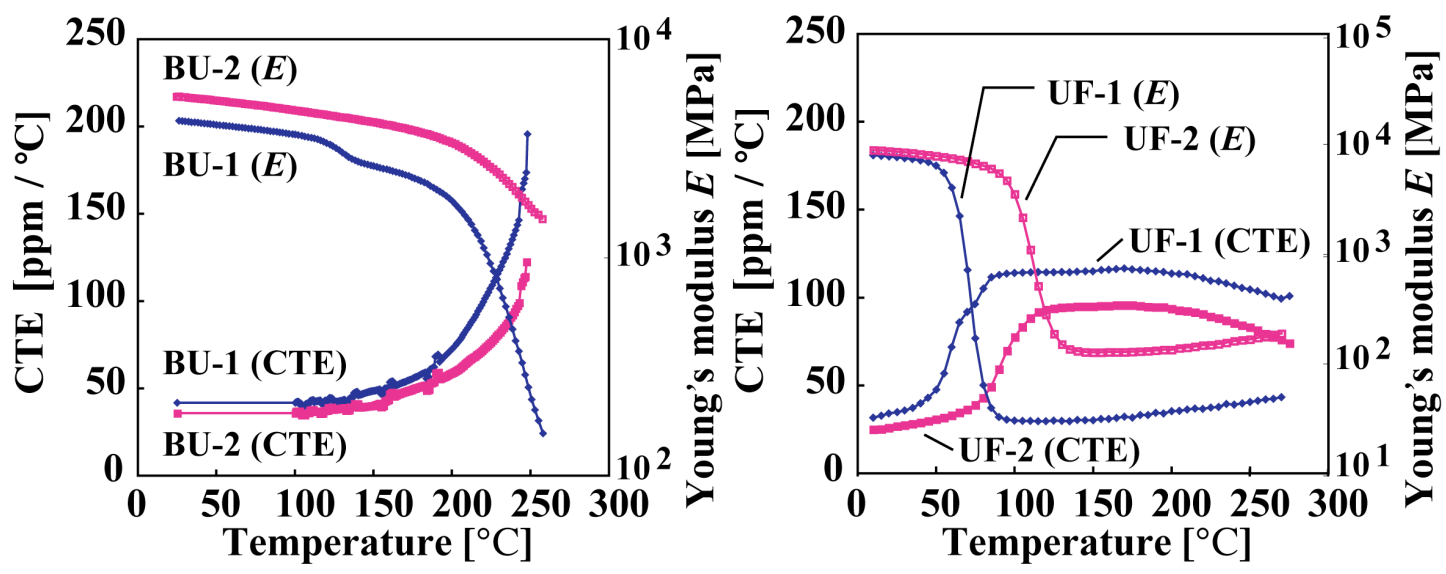

Fig. 2 Material properties of BU and UF resins.

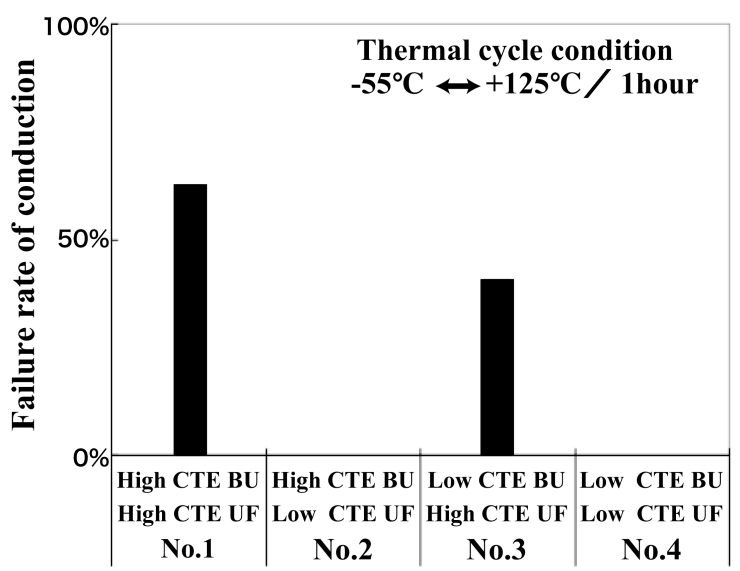

Fig. 3 Comparison of failure rates among FC packages after thermal cycle test. 


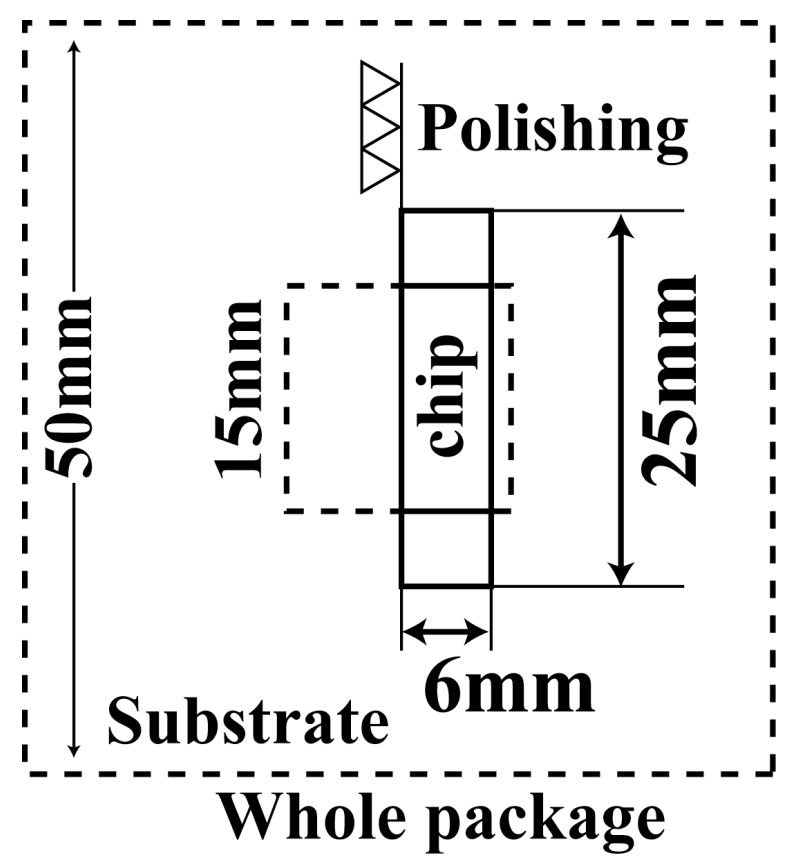

Fig. 4 Specimen cut out from a FC package.

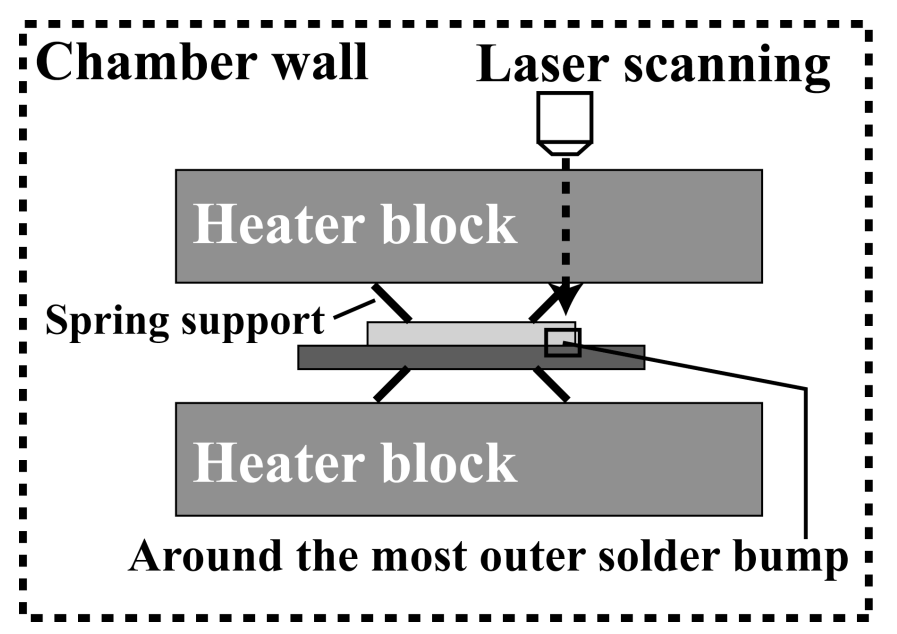

Fig. 5 Schematic of the measurement system using the DICM. 


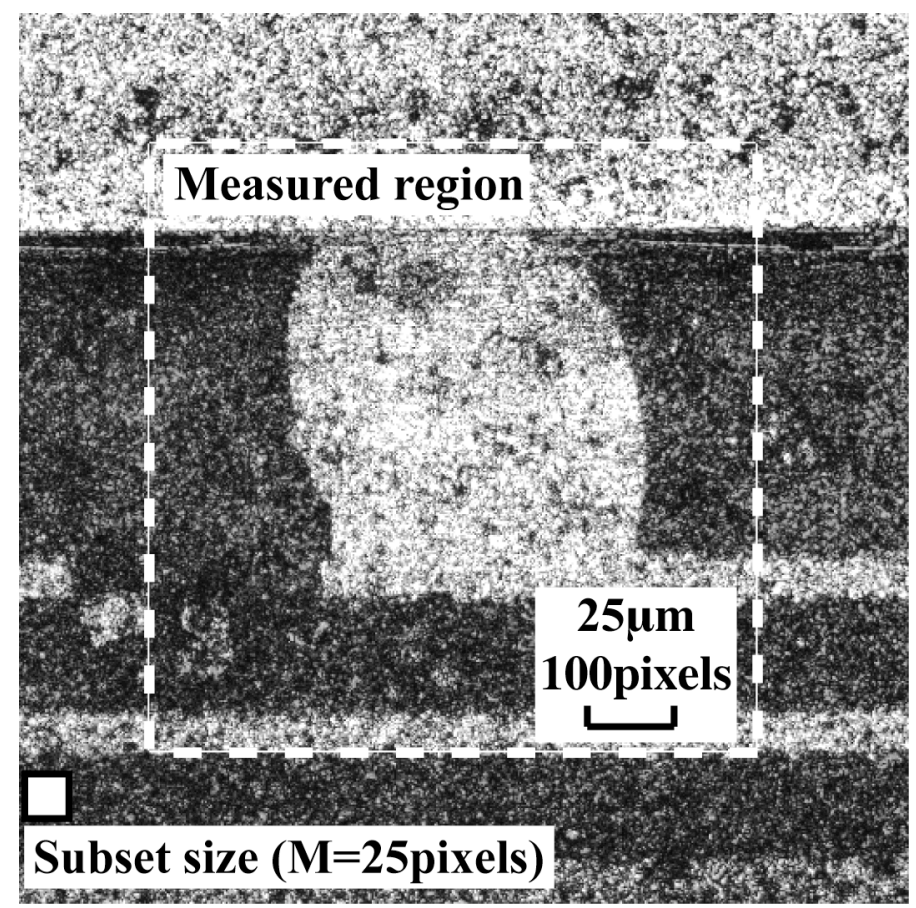

Fig. 6 Captured image around a solder bump by the CLSM.

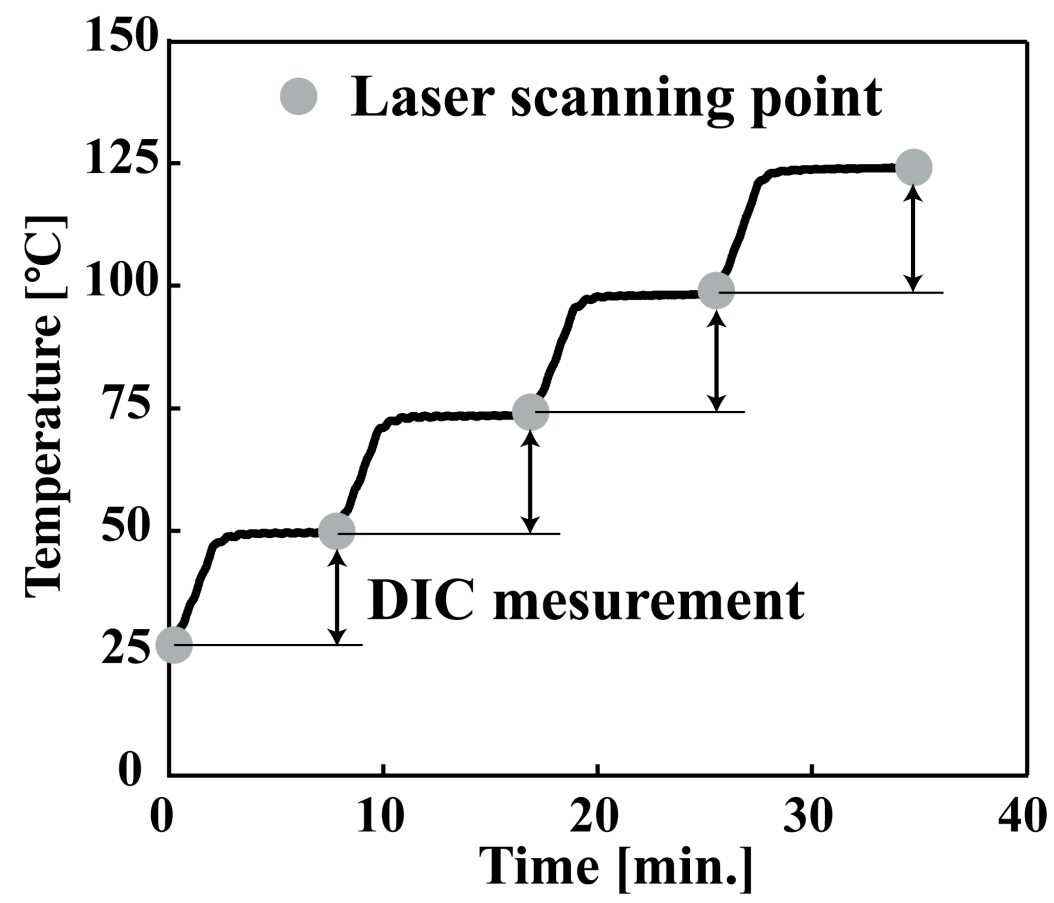

Fig. 7 Thermal history of the strain measurement. 


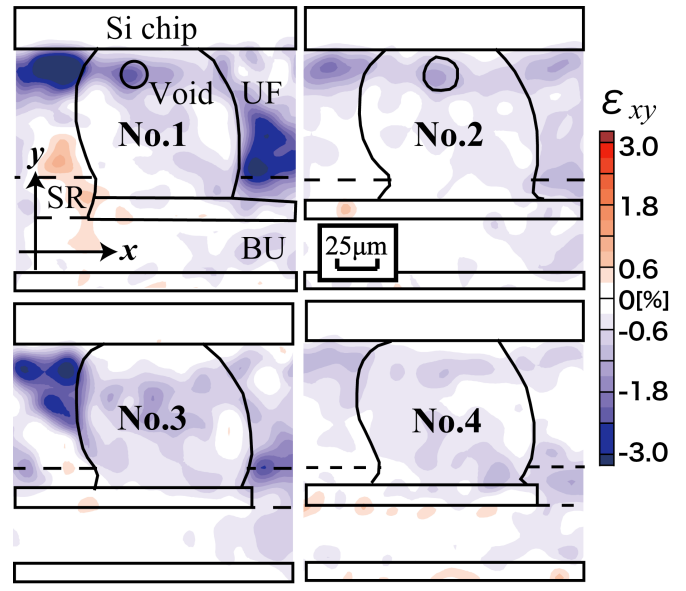

a) shear strain distribution

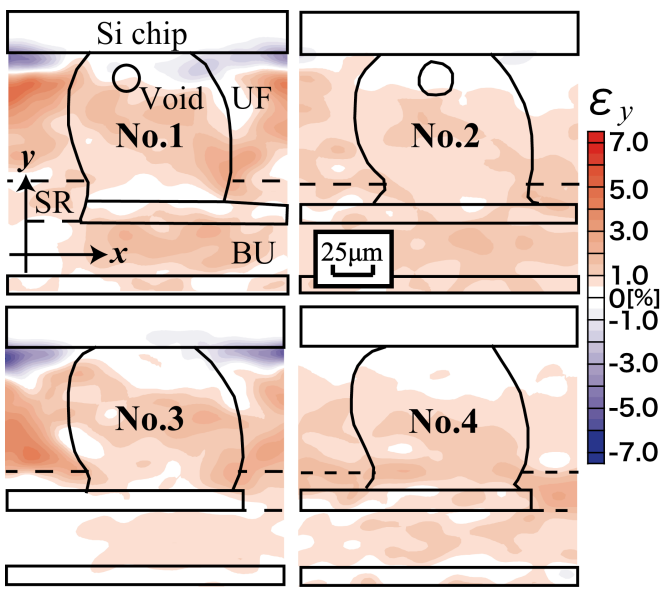

b) normal strain distribution

Fig. 8 Strain distributions measured by the DICM after heating from $25{ }^{\circ} \mathrm{C}$ to $125{ }^{\circ} \mathrm{C}$.

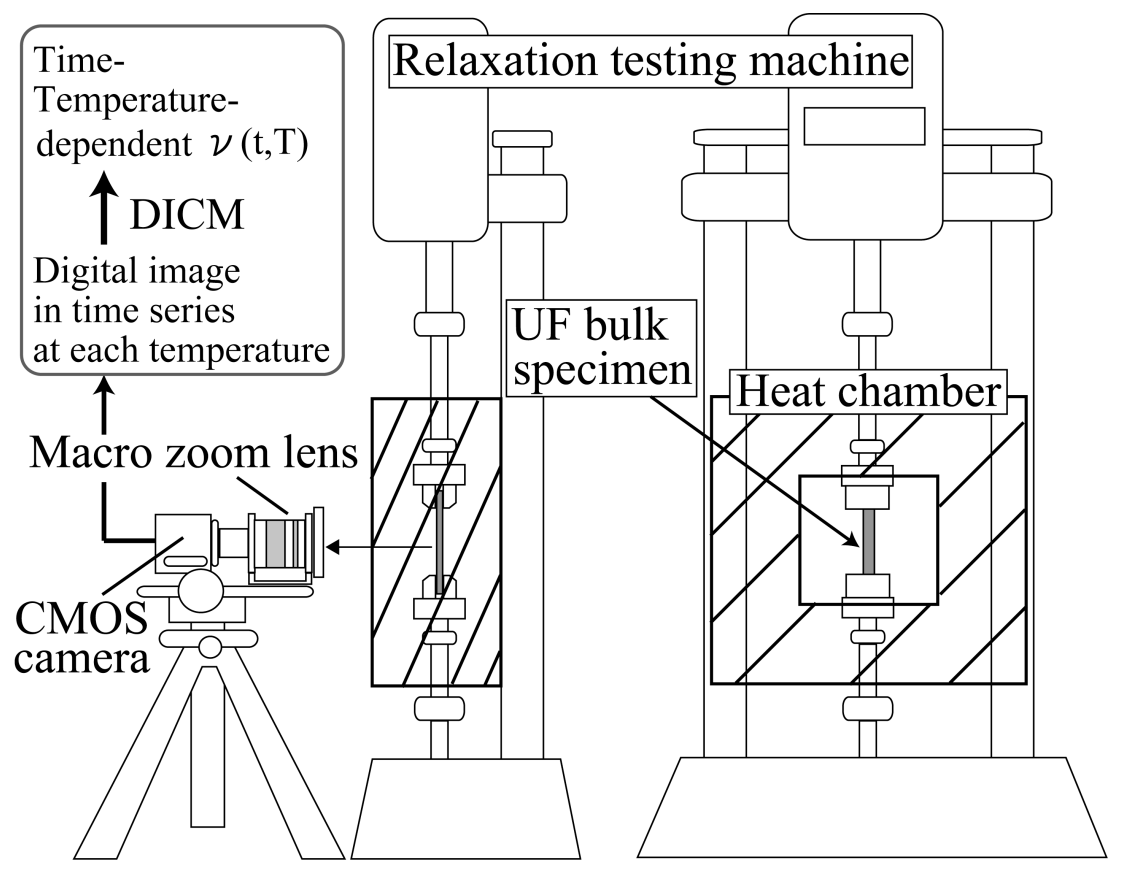

Fig. 9 Schematic of experimental apparatus for the stress relaxation test. 

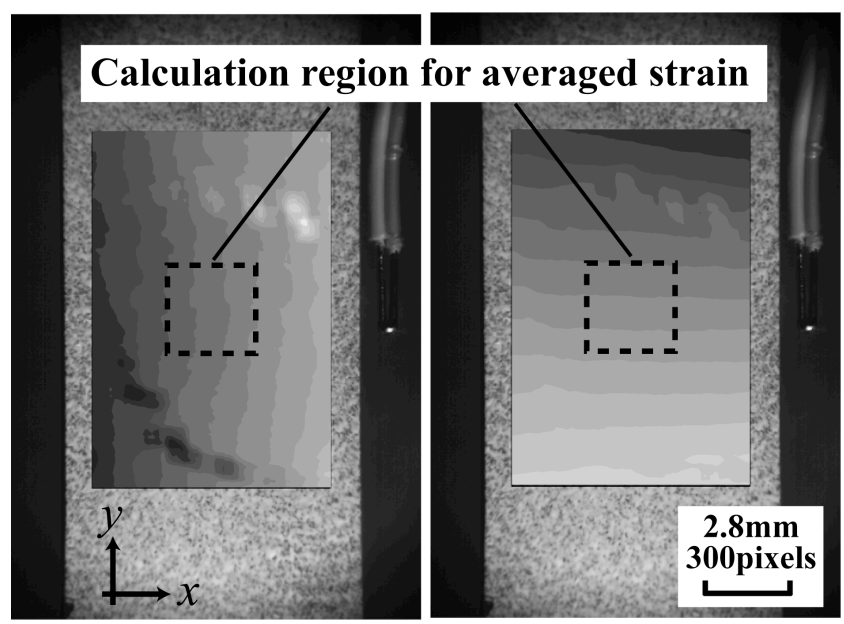

$u_{x} / u_{y}$

$162 / 210$

[ $\mu \mathrm{m}]$

$159 / 200$

$156 / 190$

$153 / 180$

$150 / 170$

$-147 / 160$

144 / 150

$141 / 140$

Fig. 10 Displacement fields during SRT and calculation region to obtain domain-averaged strain.

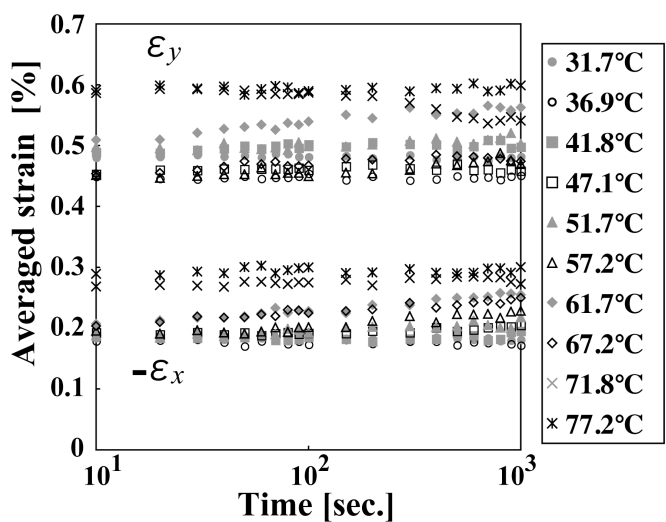

a) UF-1 resin

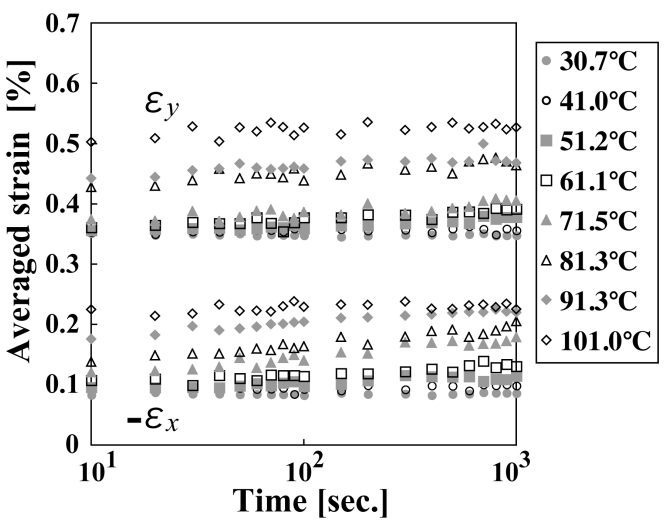

b) UF-2 resin

Fig. 11 Variations of strain with time at several temperatures during the stress relaxation test measured by the DICM. 


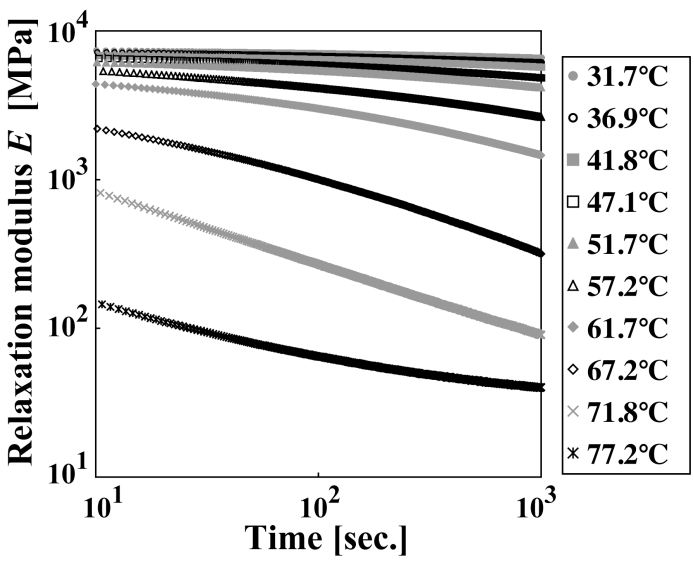

a) UF-1 resin

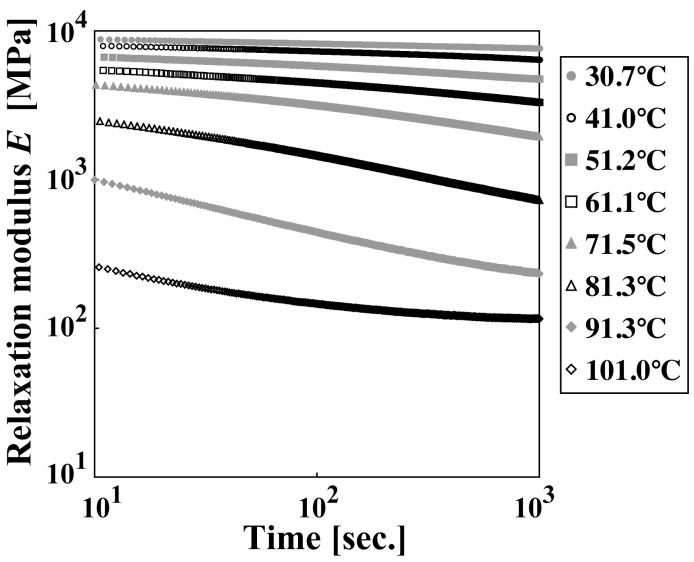

b) UF-2 resin

Fig. 12 Variations of relaxation moduli with time at several temperatures during the stress relaxation test.

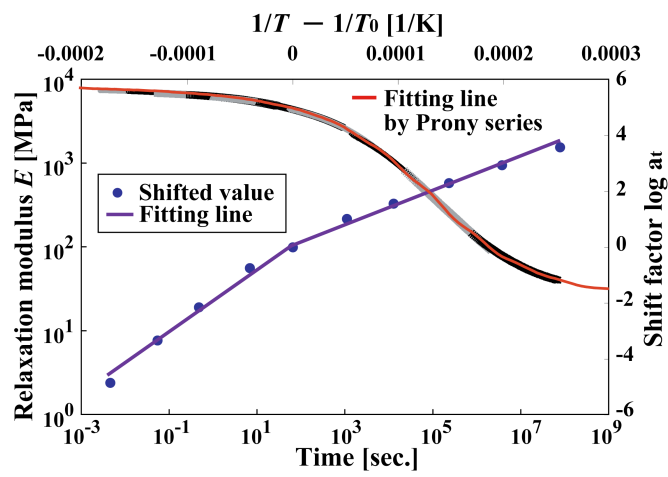

a) UF-1 $\operatorname{resin}\left(T_{0}=57.2^{\circ} \mathrm{C}\right)$

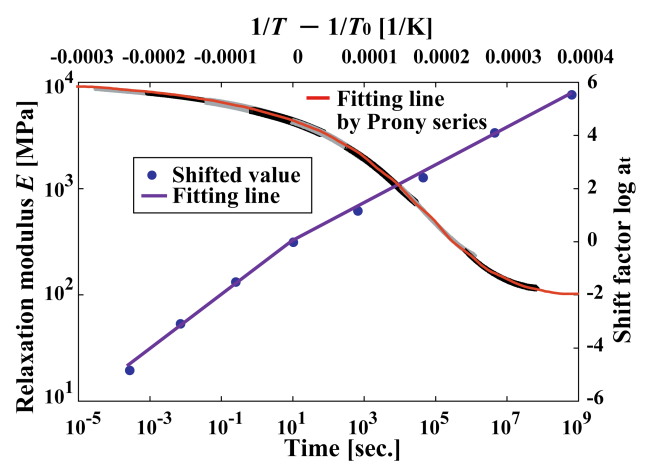

b) $\mathrm{UF}-2 \operatorname{resin}\left(T_{0}=71.5^{\circ} \mathrm{C}\right)$

Fig. 13 Master curves of relaxation moduli obtain by the measurement and the approximation curves by Prony series at the reference temperature, $T_{0}$, and their shift factors. 


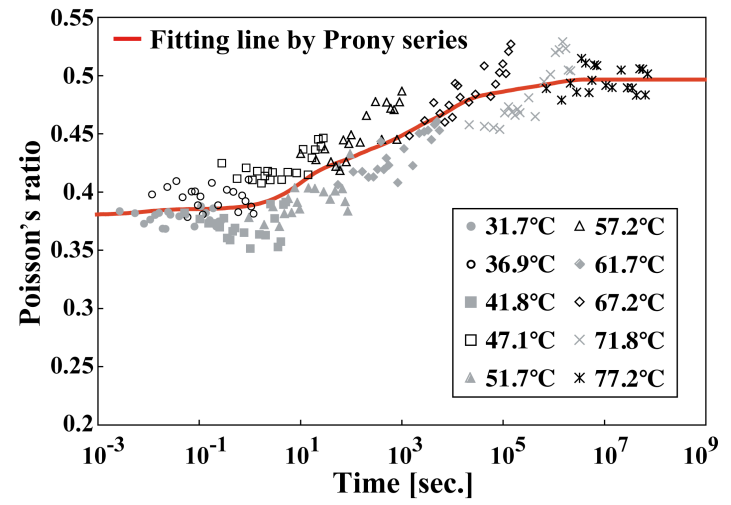

a) UF-1 $\operatorname{resin}\left(T_{0}=57.2^{\circ} \mathrm{C}\right)$

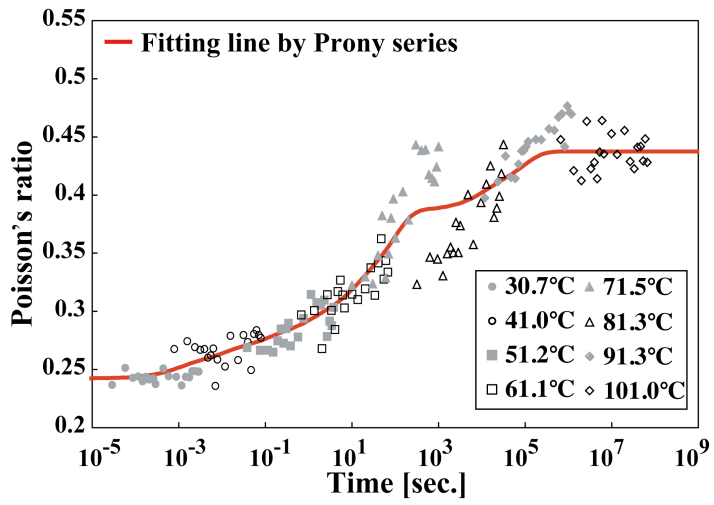

b) UF-2 $\operatorname{resin}\left(T_{0}=71.5^{\circ} \mathrm{C}\right)$

Fig. 14 Master curves of Poisson's ratios obtained by the experiment and the approximation curves by Prony series at the reference temperature, $T_{0}$.

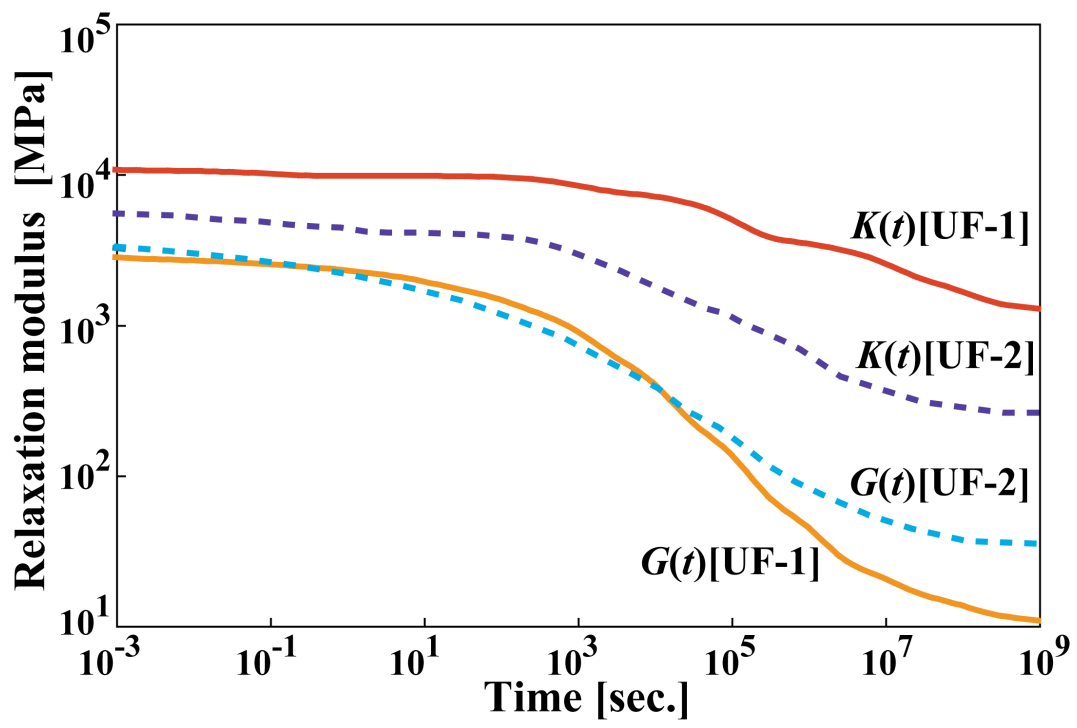

Fig. 15 Master curves of relaxation shear moduli and bulk moduli for both UF resins.

$$
\left(\mathrm{UF}-1: T_{0}=57.2^{\circ} \mathrm{C}, \mathrm{UF}-2: T_{0}=71.5^{\circ} \mathrm{C}\right)
$$




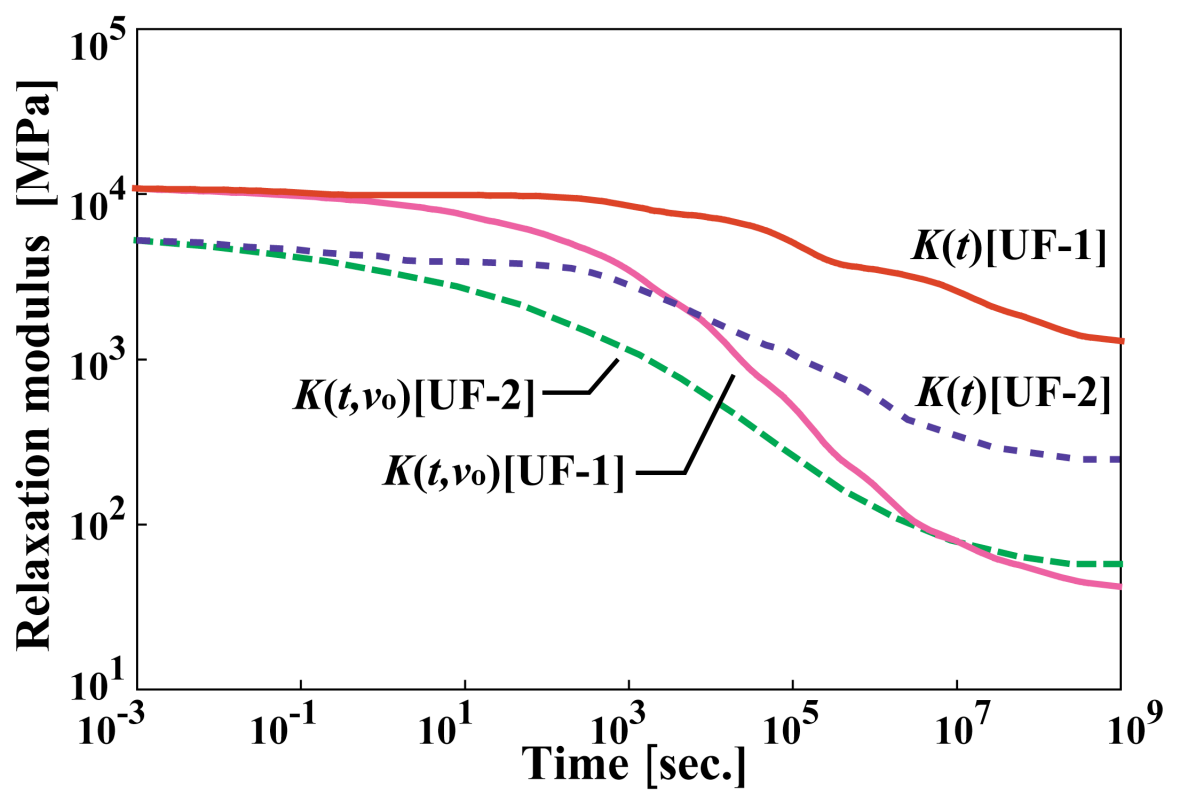

Fig. 16 Comparison of relaxation bulk moduli between $K(t)$ and $K\left(t, v_{0}\right)$.

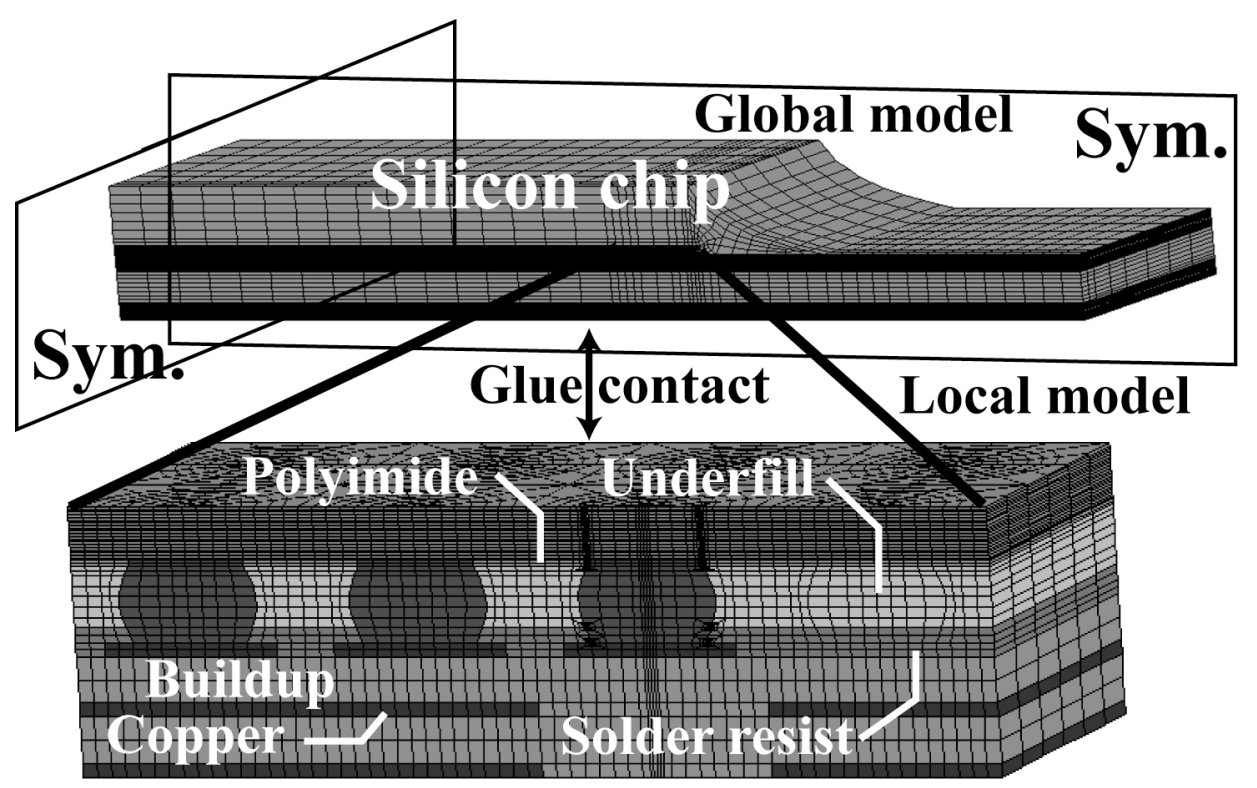

Fig. 17 1/4 symmetrical FE model of a FC package specimen. 


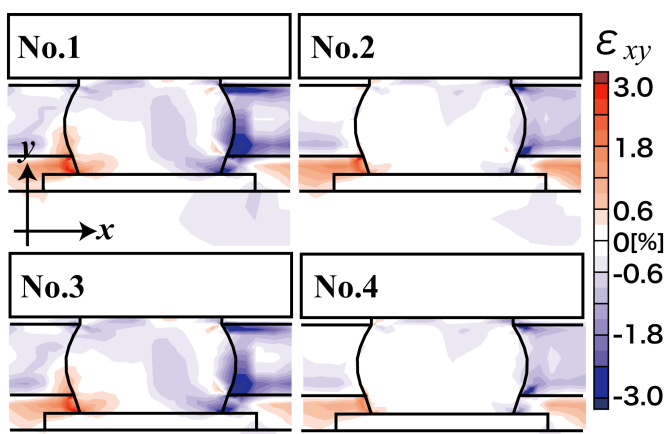

a) Shear strain distribution $\varepsilon_{x y}$

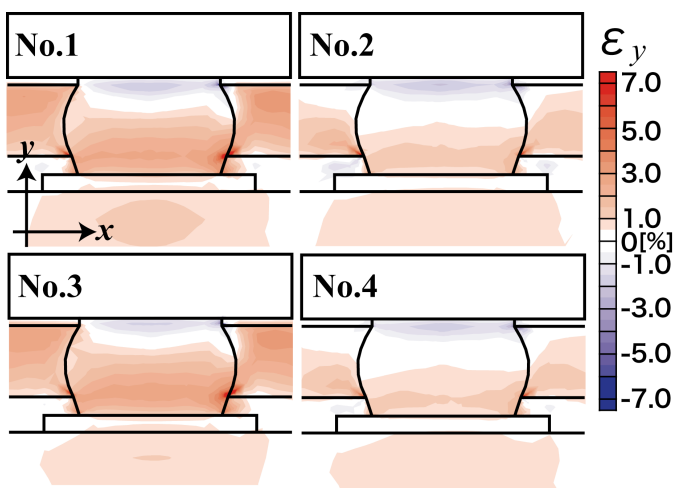

b) Normal strain distribution $\varepsilon_{y}$

Fig. 18 Strain distributions in the FE analyses after heating from $25^{\circ} \mathrm{C}$ to $125^{\circ} \mathrm{C}$ with time-temperature dependence of Poisson's ratios of UF resins (Model GK).

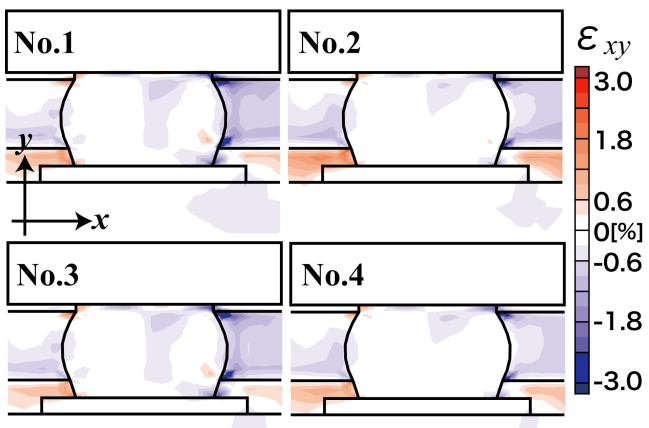

a) Shear strain distribution $\varepsilon_{x y}$

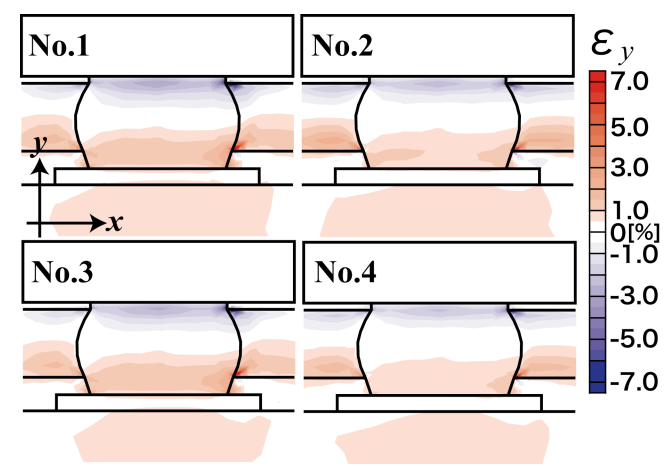

b) Normal strain distribution $\varepsilon_{y}$

Fig. 19 Strain distributions in the $\mathrm{FE}$ analyses after heating from $25^{\circ} \mathrm{C}$ to $125^{\circ} \mathrm{C}$ with the constant instantaneous Poisson's ratios of UF resins (Model G). 


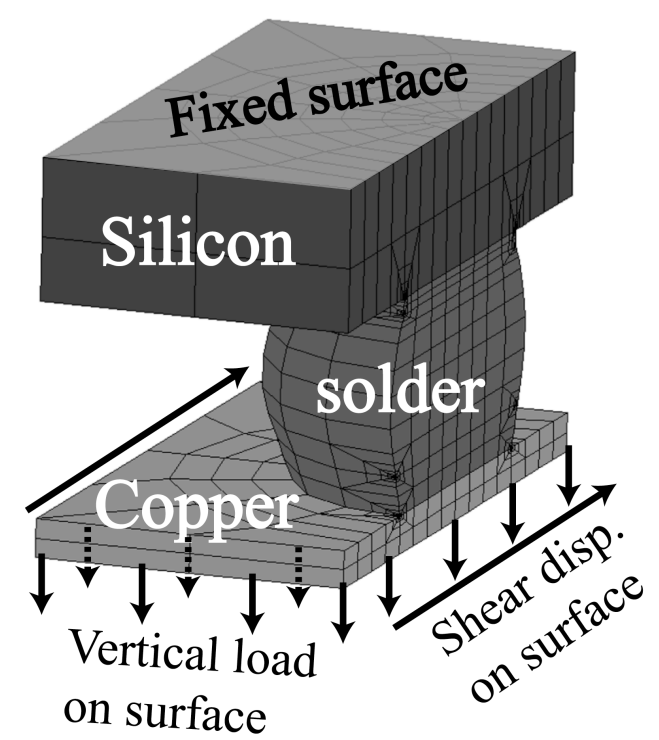

Fig. 20 Single solder bump model.

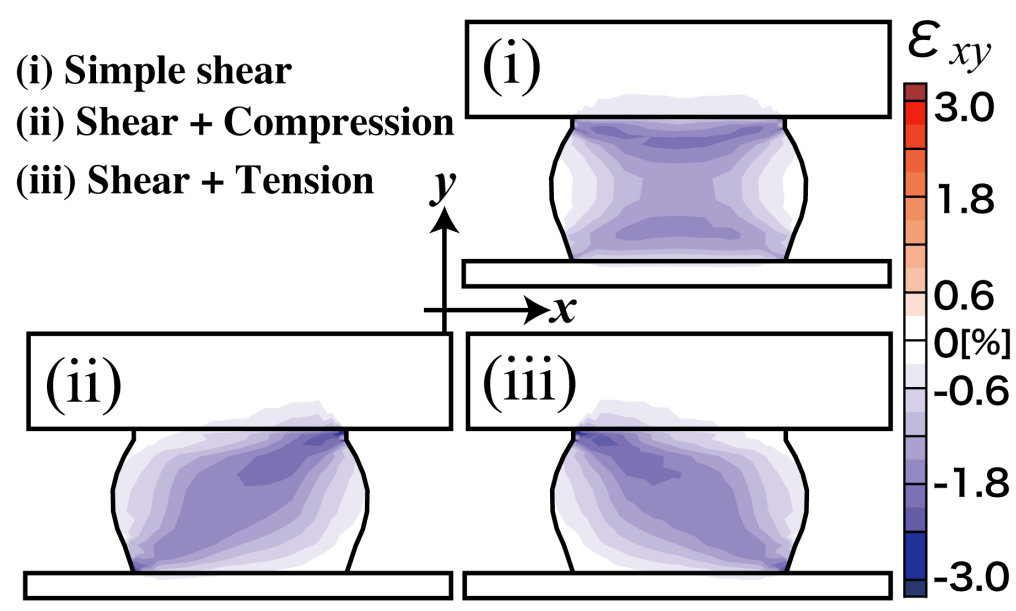

Fig. 21 Effect of vertical stress on the distributions of shear strain in a solder bump. 